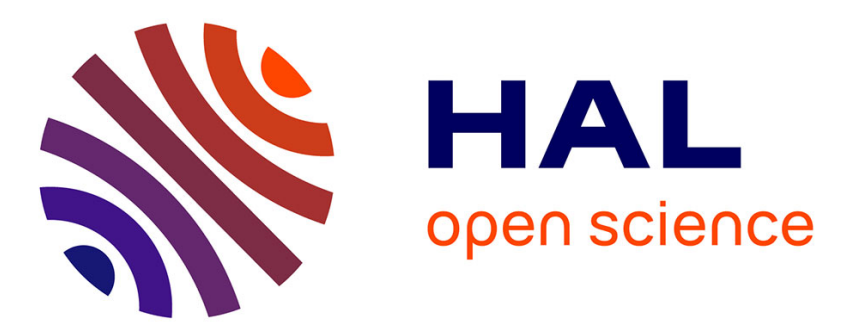

\title{
Determination of the health state of fuel cell vehicle for a clean transportation
}

\author{
Mohamed Becherif, Marie-Cécile Péra, Daniel Hissel, Zhixue Zheng
}

\section{To cite this version:}

Mohamed Becherif, Marie-Cécile Péra, Daniel Hissel, Zhixue Zheng. Determination of the health state of fuel cell vehicle for a clean transportation. Journal of Cleaner Production, 2018, 171, pp.1510 1519. hal-02130113

\section{HAL Id: hal-02130113 \\ https://hal.science/hal-02130113}

Submitted on 15 May 2019

HAL is a multi-disciplinary open access archive for the deposit and dissemination of scientific research documents, whether they are published or not. The documents may come from teaching and research institutions in France or abroad, or from public or private research centers.
L'archive ouverte pluridisciplinaire HAL, est destinée au dépôt et à la diffusion de documents scientifiques de niveau recherche, publiés ou non, émanant des établissements d'enseignement et de recherche français ou étrangers, des laboratoires publics ou privés. 


\title{
Determination of the health state of fuel cell vehicle for a clean transportation
}

\author{
Mohamed BECHERIF ${ }^{1,2}$, Marie-Cécile PERA ${ }^{1,3}$, Daniel HISSEL ${ }^{1,3}$, Zhixue ZHENG ${ }^{1,3}$ \\ ${ }^{1}$ FCLAB FR CNRS 3539, FEMTO-ST UMR CNRS 6174 , \\ ${ }^{2}$ University of Bourgogne Franche Comte/UTBM, 90010 Belfort Cedex, France \\ ${ }^{3}$ University of Bourgogne Franche Comte/UFC, 90010 Belfort Cedex, France \\ Email: Mohamed.becherif@utbm.fr
}

\begin{abstract}
The penetration of Fuel Cell vehicle in a large scale market requires efficiency, long life cycle use and health state monitoring of the key powertrain element: the fuel cell stack. This paper presents three novel methods for an efficient and rapid estimation of the Electrochemical Impedance Spectrum (EIS) of the Fuel Cell. The EIS is a very useful technique for fault detection of electrochemical systems as FC. To perform EIS, measurements at high frequencies are quite easy and rapid to perform but the measurements at low (and very low) frequencies can take a long time to proceed. This long delay to obtain those low-frequency measurements can limit the applicability of the methodology, especially when considering that stationary operating conditions of FC are quite difficult to maintain, nevertheless required for guarantying the quality of the measurements. A method allowing an accurate estimation of the FC EIS at low and very low frequencies could be of a great interest to solve this issue. Authors present different FC EIS estimation methods in order to overcome the drawback of the EIS method used in the fault detection. The three different methods are validated experimentally and the performances are compared.
\end{abstract}

Keyword: Fuel Cell, electrochemical impedance spectroscopy, fault detection. 


\section{Introduction}

The continuous rising up of the transportation needs and the rapid depletion of fossil resources make the fuel cell vehicle the suitable solution in terms of autonomy, driving dynamics, rapidity of refueling, and nonpolluting system [1-2]; However, the FC car is also requested to be efficient, green, safe, with a good life cycle [3-4]. Consequently, FC system has to be checked, monitored, and its state of health diagnosed and occurring faults prognosed.

Impedance Spectroscopy (IS) is a general term that subsumes the small-signal measurement of the linear electrical response of a material of interest (including electrode effects) and the subsequent analysis of the response to yield useful information about the physico-electrochemical properties of the system. Analysis is generally carried out in the frequency domain, although measurements are sometimes made in the time domain and then Fourier transformed to the frequency domain, see [5-9] for an in-depth review.

IS deals with complex quantities. Consequently, its history begins with the introduction of impedance into electrical engineering by Oliver Heaviside in the 1880s. This work was extended by A.E. Kennelly and C.P. Steinmetz to include vector diagrams and complex representation [5]. Soon after that, researchers began to make use of the Argand diagram of mathematics by plotting immittance response in the complex plane, with frequency as an implicit variable. Electrical engineering examples were the circle diagram introduced by C.W. Carter [9] and the Smith-Chart impedance diagram of P.H. Smith [6]. Such complex plane plots are now widely used for two-dimensional representation of the response of all immittance types. Finally, threedimensional perspective plots that involve a log-frequency axis were introduced to the IS area by the authors of [11]; these plots allow complete response at a given immittance level to be shown in a single diagram.

IS analysis makes mainly use of "electrical" equivalent circuits to represent experimental frequency response [5].

The EIS consists in the injection of a sinusoidal stimulus (in voltage or current) on a large frequency range in order to measure the impedance of the considered system. After this step, this EIS can be used to assess the state-of-health of the considered system by comparing the obtained spectrum with the healthy FC EIS signature. Different diagnosis techniques were developed during recent years depending on the application domain, among them the Electrochemical Impedance Spectroscopy (EIS) diagnosis. EIS is commonly used for the diagnosis of complex systems [15-17]. In electrochemical systems, EIS is used as the system behavior is determined by a number of strongly coupled processes [18-19].

In order to correctly perform EIS measurements, a high-quality impedance spectrometer is required covering the millihertz to megahertz frequency range. 
On the one hand, this diagnosis method allows detecting miscellaneous phenomena characterized by spectral impedance analysis. This method allows having the impedance evolutions according to the frequency, for a safe case of FC operation and to compare it with that of a faulty case.

Acquirement of an impedance spectrum covering both high and low frequency points is usually timeconsuming (up to hours) [15,20-22]. Considering real-time applications like fault diagnosis, this could be dangerous to the system if short-time faults occur during this process. Furthermore, the system being measured should remain at a steady state during the time of measuring the EIS [14]. Otherwise, information provided by EIS may be unreliable. Thus, the system delivers a constant power during all the measurement process whereas the load can require variable power. According to the literature, measurements at low frequency points usually suffer from high disturbances, which may be caused by the control of auxiliaries or occurring due to transport limitations $[23,24]$. This paper aims at estimating the whole spectrum based on only the high frequency measurements, which is more time-efficient and applicable in real-time framework. Compared with the traditional way of utilizing the whole frequency range of EIS, the proposed methods in this paper have three principle advantages. Firstly, it is less time-consuming. Since only the high frequency part is applied for estimating the whole spectrum, short time is required for the acquirement of EIS; Secondly, the drift effect linked to varying operating conditions on the spectrum could be avoided, since the low frequency points are not directly measured; Third, the high frequency part of the spectrum could be utilized to determine the normal operating range of the system. Thus, the faulty status could be predicted in an early time by detecting the discrepancy of the measured high frequency points from those obtained under normal conditions. This function is also called "prognostic" in some literature $[25,26]$.

Experimentation are conducted in order to validate the proposed methods and to explain for each method the step-by-step procedure. EIS for PEMFC are obtained in a wide frequency range from $5 \mathrm{kHz}$ to $0,05 \mathrm{~Hz}$. The whole impedance spectrum test takes several hours to be obtained. Three new methods are proposed to estimate the whole Nyquist impedance spectrum using data obtained during only few minutes.

This paper is organized as follows: Section 2 gives an overview on the diagnosis techniques using EIS method, the experimental setup is described in Section 3, The proposed three new methods for the EIS estimation (the elliptical method, the curve fitting method and the sinusoid function) are given in Section 4. In Section 5, a comparison between these three methods is illustrated and finally the conclusion in Section 6 .

\section{Diagnosis techniques using electrochemical impedance spectroscopy}

The electrical resistance is the ability of a circuit element to resist the flow of electrical current. Ohm's law defines resistance in terms of the ratio between voltage $\mathrm{E}$ and current $\mathrm{I}$ :

$$
R=E / I
$$


Real applications contain circuit elements with more complex behavior, and then impedance is used instead of resistance. Like resistance, impedance is a measure of the ability of a circuit to resist the flow of electrical current. Unlike resistance, impedance is not limited by the simplifying properties listed above.

Electrochemical impedance is usually measured by applying an $\mathrm{AC}$ potential to an element and measuring the current through it. By applying a sinusoidal potential excitation, the response is an AC current signal. This current signal can be analyzed as a sum of sinusoidal functions (Fourier series).

Electrochemical Impedance is normally measured using a small excitation signal. This is done so that the system's response is pseudo-linear. In a linear (or pseudo-linear) system, the current response to a sinusoidal potential is a sinusoid at the same frequency but shifted in phase. See Fig. 1.

Fig. 1: Sinusoidal current response in a linear system

The excitation signal, expressed as a function of time, has the form:

$$
E_{t}=E_{0} \sin (\omega t)
$$

$E_{t}$ is the potential at time $t, E_{0}$ is the amplitude of the signal, and $\omega$ is the radial frequency. The relationship between radial frequency $\omega$ (expressed in radians/second) and frequency f (expressed in hertz) is: $\omega=2 \pi \tilde{d}$

In a linear system, the response signal $I$ is shifted in phase $(\phi)$ and has a different amplitude $I_{0}$.

$$
I=I_{0} \sin (\omega t+\phi)
$$

Fig. 2 is the Lissajous figure which describes the system's complex harmonic motion.

Fig. 2: Lissajous figure

When the input to an LTI (Linear Time Invariant) system is sinusoidal, the output is sinusoidal with the same frequency. It may have different amplitude and phase shift. Using an oscilloscope that can plot one signal against another to plot the output of a LTI system against the input to the LTI system produces an ellipse.

If the applied sinusoidal signal is plotted on the $\mathrm{X}$-axis of a graph and the sinusoidal response signal $I(t)$ on the Y-axis, the Nyquist plot is obtained (Fig. 3 for a $1^{\text {st }}$ order system).

Using Euler relationship $e^{j \phi}=\cos \phi+j \sin \phi$, it is possible to express the impedance as a complex function. The potential is described as:

$$
E_{t}=E_{0} e^{j \omega t}
$$


and the current response as:

$$
I_{t}=I_{0} e^{j \omega t-\phi}
$$

The impedance is then represented as a complex number:

$$
Z(\omega)=E / I=Z_{0} e^{j \phi}=Z_{0}(\cos \phi+j \sin \phi)
$$

The impedance is therefore expressed in terms of a magnitude $Z_{o}$ and a phase shift $\phi$.

Notice that in Fig. 3, the y-axis is negative and that each point on the Nyquist plot is the impedance at one frequency. Low frequency data are on the right side of the plot and higher frequencies are on the left. On the Nyquist plot, the impedance can be represented as a vector (arrow) of length $|\mathrm{Z}|$. The angle between this vector and the $\mathrm{x}$-axis is $\phi(=\operatorname{argZ})$.

Nyquist plots have one major shortcoming by considering the frequency as an implicit variable.

Fig. 3: Nyquist plot with impedance vector

Data can be plotted either in the frequency or in time domain. A transform can be used to switch between domains. The Fourier transform takes time domain data and generates the equivalent frequency domain data.

Spectral impedance is computed from current and voltage expressions, according to the equations below and compared to the healthy spectral impedance for the FC diagnosis.

Measured signals consist on alternative (real and complex) components (voltage, current and impedance).

$$
\begin{aligned}
& U(f)=U(j \omega)=\bmod [U(j \omega)] e^{j \cdot \arg [U(j \omega)]} \\
& I(f)=I(j \omega)=\bmod [I(j \omega)] e^{j \cdot \arg [I(j \omega)]} \\
& Z(f)=Z(j \omega)=\frac{U(j \omega)}{I(j \omega)}=\bmod [Z(j \omega)] e^{j \cdot \arg [Z(j \omega)]} \\
& \left\{\begin{array}{c}
\bmod [Z(j \omega)]=\frac{\bmod [U(j \omega)]}{\bmod [I(j \omega)]} \\
\arg [Z(j \omega)]=\arg [U(j \omega)]-\arg [I(j \omega)]
\end{array}\right.
\end{aligned}
$$

Curves shown in Fig.4 illustrate the purpose of the idea proposed in this work. The black points represent the impedances acquired under normal operating conditions; the blue and green spectra are threshold lines which determine the normal operating zone. The red stars are impedance measured under faulty operating conditions. Through a detailed observation on the high frequency part in the left and lower part of Fig.4, it could be found that the faulty status could be predicted based on the high frequency points without the 
necessity of waiting for the whole spectrum. This is quite beneficial for the health status of fuel cell stacks [26-28]. The experimental data in Fig. 4 are obtained from the European Project D-CODE FP7 dedicated to the on-line diagnosis of a Proton Exchange Membrane (PEM) fuel cell system.

Fig.4 An example for fault prediction based on experimental data in real case: top=whole Nyquist plot, bottom: zoom on

Nyquist plot

\section{Experimental setup}

A 20-cell stack has been used to perform the EIS. The active surface of the cells is $100 \mathrm{~cm}^{2}$. The stack is operated on a test bench that has been designed and realized in the laboratory as shown in Fig. 5. The operating conditions are kept constant all along the EIS and are the following:

-control input gas flow at stoichiometry factors 1.8 and 3 at the anode and the cathode respectively;

-humidify input air and hydrogen with a relative humidity $35 \%$ and $75 \%$ respectively;

-stack operating temperature is set as $80^{\circ} \mathrm{C}$;

-current density is $0.2 \mathrm{~A} / \mathrm{cm}^{2}$.

The EIS is measured through a home-made spectrometer in a Galvanostatic mode [24]. The amplitude of the sinusoidal perturbation is $7.5 \%(1.5 \mathrm{~A})$. The frequency is varied from $5 \mathrm{kHz}$ to $0.05 \mathrm{~Hz}$, with ten and five frequencies per decade for the frequency range $5 \mathrm{kHz}-1 \mathrm{~Hz}$ and $1 \mathrm{~Hz}-0.05 \mathrm{~Hz}$ respectively. The impedance is calculated from the mean value obtained from 10 periods when frequency is superior to $10 \mathrm{~Hz}$ and from 5 periods when frequency is inferior to $10 \mathrm{~Hz}$. It means that at $5 \mathrm{kHz}$, the acquisition takes $2 \mathrm{~ms}$ but at $0.05 \mathrm{~Hz}$ it takes about 1.6 minutes. The low frequency impedances are then much more time consuming to measure than the high frequency ones.

Fig.5 EIS test bench [24]

When considering PEM Fuel Cells, under nominal operating conditions, the experimental EIS spectrum presents classically the shape given in Fig.6. On this spectrum, moving from the right to the left of the spectrum, an evolution from the (very) low frequencies (about $0,05 \mathrm{~Hz}$ ) to the high frequencies (about $5 \mathrm{kHz}$ ) can be obtained.

Fig.6. Experimental FC EIS (axes are in $\mathrm{m} \Omega$ ) 
Regarding the experimental FC EIS obtained on Fig.6, different extrapolation methods can be proposed in order to reproduce the actual FC EIS behavior, from only a narrow high-frequency-range (and non-time consuming) measurements. Three EIS estimation methods are here proposed by authors, based on the Nyquist impedance plot (theoretical one given in Fig. 3 and experimental one of Fig. 4), authors have proposed the mathematical formula like sinusoidal and ellipse (using the motion equation of a projectile) functions, which are close to the Nyquist shape and the classical curve fitting method. These methodologies will be detailed in the next sections.

\section{EIS estimation using the proposed new methods}

\subsection{EIS estimation using elliptical function}

An ellipse is a smooth closed curve, which is symmetric about its horizontal and vertical axes. The distance between antipodal points on the ellipse, or pairs of points whose midpoint is at the center of the ellipse, is maximum along the major axis or transverse diameter, and a minimum along the perpendicular minor axis. The equation of an ellipse whose major and minor axes coincide with the Cartesian axes and centered at $\left(\mathrm{x}_{0}, \mathrm{y}_{0}\right)$ is

$$
\left(\frac{x-x_{0}}{a}\right)^{2}+\left(\frac{y-y_{0}}{b}\right)^{2}=1
$$

Where $\mathrm{a}$ and $\mathrm{b}$ are the half distance of the major and minor axes $(\mathrm{a}>\mathrm{b})$

\subsubsection{Motion equation of a projectile}

The trajectory of a projectile is directly influenced by gravity (Fig. 7). In projectile motion, the horizontal motion is independent from the vertical one.

Fig. 7. Projectile trajectory motion

$\mathrm{g}$ is the gravity acceleration, $d$ is the maximum distance on the $\mathrm{x}$-axis, $\theta_{\mathrm{T}}$ is the initial projectile Trajectory angle and $\mathrm{V}_{0}$ is the initial speed.

$$
V_{0}=\left[\begin{array}{l}
V_{0 X} \\
V_{0 Y}
\end{array}\right]
$$

The components $\mathrm{V}_{0 \mathrm{X}}$ and $\mathrm{V}_{0 \mathrm{Y}}$ are function of the angle $\theta_{\mathrm{T}}$ :

$$
V_{0 X}=V_{0} \cos \left(\theta_{T}\right)
$$




$$
V_{0 Y}=V_{0} \sin \left(\theta_{T}\right)
$$

Since there is no acceleration in the horizontal direction, the vertical motion of the projectile is the motion of a particle in free fall. The components of the acceleration are: $a_{X}=0 ; a_{Y}=-g$

The horizontal component of the velocity remains unchanged throughout the motion. The vertical component of the velocity increases linearly, because the acceleration is constant. At any time t, the components of the velocity are:

$$
\begin{aligned}
& V_{X}=V_{0} \cos \left(\theta_{T}\right) \\
& V_{Y}=V_{0} \sin \left(\theta_{T}\right)-g . t
\end{aligned}
$$

The magnitude of the velocity is given using Pythagorean theorem:

$$
V=\sqrt{V_{X}^{2}+V_{Y}^{2}}
$$

The projectile displacement is given by:

$$
\begin{aligned}
& x(t)=V_{0} \cos \left(\theta_{T}\right) \cdot t \\
& y(t)=V_{0} \sin \left(\theta_{T}\right) \cdot t-\frac{1}{2} g \cdot t^{2}
\end{aligned}
$$

The maximum height of projectile is obtained when $V_{Y}=0$ :

$$
h=\frac{V_{0}^{2} \sin ^{2}\left(\theta_{T}\right)}{2 g}
$$

The maximum distance of projectile is obtained when $\mathrm{y}=0$ :

$$
d=\frac{V_{0}^{2} \sin \left(2 \theta_{T}\right)}{g}
$$

Consider the equations (18) and (19) and eliminating time between them give the parabolic trajectory:

$$
y=\tan \left(\theta_{T}\right) \cdot x-\frac{g}{2 V_{0}^{2} \cos ^{2}\left(\theta_{T}\right)} \cdot x^{2}
$$

\subsubsection{Step-by-step procedure for the EIS estimation using analytic ellipse:}


1- Measure the first EIS points (at high frequencies (here between $5 \mathrm{kHz}$ and $200 \mathrm{~Hz}$ ) =during very short time) $\mathrm{P}_{\mathrm{i}}\left(\mathrm{x}_{\mathrm{i}}, \mathrm{y}_{\mathrm{i}}\right)$, where $\mathrm{P}_{\mathrm{i}}$ is the point "i" having the coordinates $\mathrm{xi}$ (frequency) and $\mathrm{y}_{\mathrm{i}}$ (impedance measured at xi) ${ }^{1}$.

2- Calculate the initial speed $\mathrm{V}_{0}$, by:

$$
\begin{aligned}
& V_{X}=\frac{x_{i}-x_{i-1}}{T}, V_{Y}=\frac{y_{i}-y_{i-1}}{T}, \mathrm{~T} \text { is the time between the two measures Pi-1 and Pi } \\
& V=\sqrt{V_{X}^{2}+V_{Y}^{2}}
\end{aligned}
$$

3- Measure $\theta_{\mathrm{T}}$ by:

$$
\tan \theta_{T}=\frac{y}{x} ; \quad \theta_{T}=\arctan \frac{y}{x}=\arctan \frac{V_{Y}}{V_{X}}
$$

4- Calculate the maximum distance given by (21)

In (21), g represents the gravity acceleration in the case of a projectile. But, in this estimation purpose, $g$ can play the role of an adaptation gain according to the system dynamic (here $\mathrm{g}$ is chosen to be constant).

5- Plot all the estimated EIS points using (22)

Finally, the whole estimated EIS of the FC can be plotted without waiting for the low frequency measures.

Fig. 8 represents the FC EIS estimation using the ellipse equation and the projectile trajectory. Only three measures are sufficient to identify the ellipse parameters. The three measures should be carefully chosen in order to obtain a good estimation of the trajectory (eliminate the noised measures and very close ones). The two chosen points from the experimentation results are the $10^{\text {th }}(500 \mathrm{~Hz})$ and the $16^{\text {th }}(200 \mathrm{~Hz})$ experimental points + the initial point that represents the offsite of the ellipse. The choice of these $10^{\text {th }}$ and $16^{\text {th }}$ points is made in order to avoid the use of the very first noisy points, and to have enough distance between them. Generally, each fuel cell is firstly characterized in a normal and healthy situation. This characterization step (using classical EIS) can be used to give indication about the significant frequencies to be chosen when using this new method.

Fig. 8. Experimental EIS data and the EIS estimation using the analytic ellipse equation (axes are in $\mathrm{m} \Omega$ )

\footnotetext{
${ }^{1}$ The number of the needed points and their frequencies will define the accuracy of the estimation. This fact will be discussed and compared in the next sections.
} 


\subsection{EIS estimation using Curve Fitting}

Curve fitting is the process of constructing a curve, or mathematical function that has the best fit to a series of data points. Curve fitting can involve either interpolation, where an exact fit to the data is required, or smoothing, in which a "smooth" function is constructed that approximately fits the data. Fitted curves can be used as an aid for data visualization and to infer values of a function where no data are available. Extrapolation refers to the use of a fitted curve beyond the range of the observed data, and is subject to a greater degree of uncertainty since it may reflect the method used to construct the curve as much as it reflects the observed data.

Regarding the obtained experimental EIS, the curve is fitted using the following sinusoidal function:

$$
y_{\text {fit }}=A \sin (B . x)+C
$$

Where $\mathrm{y}_{\mathrm{fit}}$ is the fitted impedance imaginary part and $\mathrm{x}$ is the impedance real part. A, B and C are constant parameters to be tuned. If the fitting method has access to the whole data, the parameters estimation will be very accurate. If the data range decreases, the parameters estimation allows the estimation of a less accurate sinusoid function.

The determination of the parameters is obtained by minimizing the following cost function (least square method):

$$
\sum_{A, B, C}^{i=m}\left(y(i)-y_{f i t}(i)\right)^{2}
$$

$m \leq n$, where $\mathrm{n}$ is the maximum number of the experimental data sample. This cost function is minimized using the Matlab-Simulink Design Optimization tool

A high number of the data sample used in the curve fitting provides the best curve fitting, but the estimation of the future EIS point will not have sense because the estimation proposed here aims to gain time by using only high frequencies data. In the contrary, few data sample (at high frequency) allows estimating the points in the lower range of frequency but the performance of the curve fitting will decrease. A compromise should be done about the choice of the data sample used in the curve fitting.

Fig. 9. Experimental FC EIS data and the obtained curve fitting using $80 \%, 70 \%$ and $60 \%$ of the experimental data sample (axes are in $\mathrm{m} \Omega$ ).

The obtained estimation with sinusoidal curve fitting for different percentages of data used impose to use $80 \%$ of the experimental EIS data in order to obtained good performance (Fig. 9). This method allows then to 
estimate the remaining $20 \%$ points. The acquisition of $80 \%$ of the data takes about $33 \mathrm{~s}$ whereas the remaining $20 \%$ takes about $8,5 \mathrm{mn}$.

The absolute values of errors between each estimation and the actual values are calculated in percentage:

Percentage of error with $80 \%$ of data $=10,7 \% \quad$ (this takes 33 seconds for measurement)

Percentage of error with $70 \%$ of data $=41,5 \% \quad$ (this takes 11 seconds for measurement)

Percentage of error with $60 \%$ of data $=82,3 \% \quad$ (this takes 3,3 seconds for measurement)

Fig. 10 shows the accuracy of the estimation of the whole EIS using the curve fitting method. One can find in the y-axis the percentage of the estimation error as function of the percentage of the used data in the curve fitting method. It is clear that the more data used the more accurate the estimation is. This curve gives indication to the user on how much data he needs for a given percentage of error estimation.

Fig. 10. Percentage of estimation error versus percentage of used data for the curve fitting estimation

\subsection{EIS estimation using sinusoidal function}

The FC EIS is estimated using the following proposed sinusoidal function

$$
y=A \sin (B \cdot x+C)+D
$$

Where $\mathrm{A}, \mathrm{B}, \mathrm{C}$ and $\mathrm{D}$ are constant parameters to be tuned. $\mathrm{y}$ and $\mathrm{x}$ are the impedance imaginary and real parts, respectively.

- The maximal distance equation (21) can be used in order to evaluate the pulse $\mathrm{B}$, since that the distance $d$ can be considered as the half period. Consequently:

$$
B=\frac{\pi}{d}
$$

Using $\mathrm{P}_{0}\left(\mathrm{x}_{0}, \mathrm{y}_{0}\right)$

- D corresponds to the offset in the y-axis obtained with the first EIS measure ( $\left.\mathrm{y}_{0}\right)$, then

$$
\mathrm{D}=\mathrm{y}_{0} \text {. }
$$

_ $y_{0}=A \sin \left(B \cdot x_{0}+C\right)+y_{0}$

$$
\Leftrightarrow C=-B \cdot x_{0}
$$

Using $\mathrm{P}_{1}\left(\mathrm{x}_{1}, \mathrm{y}_{1}\right)$

$$
y_{1}=A \sin \left(B \cdot\left(x_{1}-x_{0}\right)\right)+y_{0}=A \sin \left(\frac{\pi}{d} \cdot\left(x_{1}-x_{0}\right)\right)+y_{0}
$$




$$
A=\frac{y_{1}-y_{0}}{\sin \left(\frac{\pi}{d} \cdot\left(x_{1}-x_{0}\right)\right)}
$$

Fig. 11. Experimental FC EIS data and the EIS estimation using the analytic sinusoidal equation (axes are in $\mathrm{m} \Omega)$.

Fig. 11. gives the EIS estimation using an analytic sinusoidal function and determining the different parameters using equations (27)-(30) and (21). The estimated EIS is very close to the experimental EIS data even if very few points (at a high frequency) were used in the parameters identification (minimum two points + the initial one are needed).

\section{Comparison between the different EIS estimation methods}

Fig. 12. presents the experimental FC EIS and the EIS estimation using the three proposed methods. The three estimated curves are quite close to the real EIS. They have to be compared in terms of estimation accuracy, number of real data used for the estimation, time consumption and number of parameters to be tuned.

Fig. 12. Experimental FC EIS data and the EIS estimation using the curve fitting (with $80 \%$ data), the analytic ellipse equation and the analytic sinusoidal equation (axes are in $\mathrm{m} \Omega$ ).

Table 1 summarizes the different results and exhibits the advantages and disadvantages of each method.

Table 1. Comparison between the different EIS estimations for the FC prognostic.

The absolute values of errors between each estimation and the actual values are calculated in percentage:

- Percentage of error with curve fitting estimation and $80 \%$ of data $=10,72 \% \quad$ (this takes 33 seconds for measurement)

- Percentage of error with sinusoidal function estimation $=11,0 \%$ (this takes 0,26 seconds for measurement)

- Percentage of error with ellipse function estimation $=21,6 \% \quad$ (this takes 0,26 seconds for measurement)

This quantitative comparison between the results obtained with the three proposed methods shows that the EIS estimation using the curve fitting method with $80 \%$ of the real data is the more accurate. However, the 
curve fitting using $80 \%$ of the data is more time consuming than the two other methods. The EIS estimation using the sinusoidal function is accurate because only three frequency points are used as input data for the whole EIS estimation providing $11 \%$ of estimation error. However, the sinusoidal function estimation method needs the tuning of four parameters in order to be used. The third method is also requiring only three frequency points as input data, needs only three parameters to be tuned but has $21,6 \%$ of EIS estimation error. Three new methods are proposed:

\section{1- Curve fitting}

2- Analytic ellipse function

3- Analytic sinusoid function

Analytic ellipse function is the simplest one because it uses measurement from only three frequencies and needs to estimate only three parameters.

Regarding the two analytic methods (sinusoidal and ellipse functions), only three inputs data are chosen among the 43 total points. The chosen data are the $10^{\text {th }}$ and $16^{\text {th }}$ points + the initial point that plays the role of the offset.

The curve fitting, compared to the two others, is the most time consuming because it needs more than $80 \%$ of the measured data to be accurate.

\subsection{Frequency points choice motivations}

The choice of the three frequency points for the sinusoidal and ellipse methods is important for obtaining a good EIS estimation. The first frequency is chosen from the first points (or the very first one if the measurement is well performed). The first point $\left(\mathrm{P}_{0}\right)$ is corresponding to the maximum frequency that can be applied for the EIS characterization $(5 \mathrm{kHz}$ in our case). The choice of frequencies two (point $\mathrm{P}_{1}$ ) and three (point $\mathrm{P}_{2}$ ) can be more difficult. The following sensitivity analysis is conducted in order to give guidance for this choice.

$\mathrm{P}_{0}$ is obtained at $\mathrm{fmax}=5 \mathrm{kHz}$

$\mathrm{P}_{1}$ is obtained at $10 \%$ of fmax $=500 \mathrm{~Hz}$. $\mathrm{P} 1$ is taken one decade lower than the maximum frequency.

$\mathrm{P}_{2}$ is obtained at $4 \%$ of $\mathrm{fmax}=200 \mathrm{~Hz}$

$\mathrm{P}_{1}$ is chosen one decade lower than the maximum frequency, this distance should be always chosen because at one decade far from the maximum frequency, the system can exhibit different characteristic than those of the very fast frequency (fmax). Hence, the point $P_{1}$ is kept and the point $P_{2}$ is changed in order to calculate the sensitivity of the choice regarding $\mathrm{P}_{2}$. In another hand, $\mathrm{P} 2$ should not be chosen too close to $\mathrm{P} 1$ in order to have a good representative point.

The sensitivity results for the choice of the $\mathrm{P}_{1}$ and $\mathrm{P}_{2}$ points regarding the analytical methods (sinusoidal and ellipse) are given in Table 1.

Table 2. Sensitivity results regarding the choice of frequencies for the sinusoidal and ellipse estimation methods. 
Fig. 13 shows the position of the three chosen points $\mathrm{P}_{0}, \mathrm{P}_{1}$ and $\mathrm{P}_{2}$ used in the analytical methods (sinusoidal and ellipse) for the EIS estimation. It can be clearly understood that the first point $\mathrm{P}_{0}$ corresponds to the maximum frequency that can be applied from the EIS converter for the EIS characterization and that this point correspond to an offset for the estimation methods. $\mathrm{P}_{1}$ is chosen at $10 \%$ of fmax and $\mathrm{P}_{2}$ at $4 \%$ of fmax regarding the results of the sensitivity analysis.

\section{Conclusion}

This work constitutes a first attempt to estimate the impedance of the fuel cell using the impedance spectrometry. Fuel cell EIS can give important information regarding the FC health that can be used in the diagnosis or control purposes. However, performing EIS measurement can be time consuming, especially when dealing with low and very low frequencies. During measurement at very low frequency (tens of millihertz for e.g.), operating conditions may change rending the diagnosis task more complicated. In addition, in the presence of a fault, EIS measurement can be as much time consuming as the system can dramatically suffer from a severe fault. The proposed methods allow estimating the FC impedance at low and very low frequencies based on few measurements at the high frequency. Different analytical methods have been developed, proposed, compared and experimentally validated. The developed methods are based on the projectile motion trajectory, on curve fitting and on an estimation based on sinusoidal function. The results are satisfactory and allow having a good estimation of the complete EIS measurement in a very short time. A potential disadvantage is that information about the frequency may be lost. For diagnostic methods, which take frequency information as input variable, this could bring some inconveniences.

\section{Reference}

[1] Rutvik Vasudev Lathia, Kevin S. Dobariya, Ankit Patel, "Hydrogen Fuel Cells for Road Vehicles", Journal of Cleaner Production, Volume 141, 10 January 2017, Page 462

[2] R. van den Hoed, "Sources of radical technological innovation: the emergence of fuel cell technology in the automotive industry", J. Clean. Prod., 15 (2007), pp. 1014-1021

[3] S. Cherubini, G. Iasevoli, L. Michelini, "Product-service systems in the electric car industry: critical success factors in marketing", J. Clean. Prod. Volume 97, 15 June 2015, Pages 40-49

[4] Sara Evangelisti, Carla Tagliaferri, Dan J.L. Brett, Paola Lettieri, "Life cycle assessment of a polymer electrolyte membrane fuel cell system for passenger vehicles », Journal of Cleaner Production, Volume 142, Part 4, 20 January 2017, Pages 4339-4355

[5] J. R. Macdonald, "Impedance Spectroscopy”, Annals of Biomedical Engineering, Vol. 20, pp. 289-305, 1992 
[6] E. Barsoukov and J.R. Macdonald, “Impedance spectroscopy: Theory, Experiment, and Application”, 2 $2^{\text {nd }}$ ed. Wiley Inter-science Publications, 2005.

[7] A.J. Bard and L.R. Faulkner, "Electrochemical Methods: fundamentals and applications", Wiley, Interscience Publications, 2000.

[8] E. Barsoukov and J.R. Macdonald, "Impedance spectroscopy: theory, experiment, and applications," $2^{\text {nd }}$ Edition, J. Wiley and sons Edition, 2005.

C.W. Carter, "Impedance of networks containing resistances and two reactances". Bell Sys. Tech. J. 4:387-401; 1925.

[9] P.H. Smith, “Transmission line calculator”, Electronics 12:29-31; 1939.

[10] J.R. Macdonald, J. Schoonman,.A.P. Lehnen, "Three dimensional perspective plotting and fitting of immittance data", Solid State lonics 5:137-140; 1981.

[11]J. Evgenij Barsoukov, J.R. Macdonald, "Impedance spectroscopy: theory, experiment, and applications," 2nd Edition, J. Wiley and sons Edition, 2005.

[12]P.W. Atkins, Physical Chemistry, Oxford University Press 1990.

[13] S. Wasterlain, D. Candusso, F. Harel, D. Hissel, et X. François, “Development of new test instruments and protocols for the diagnostic of fuel cell stacks ", J. Power Sources, vol. 196, no 12, pp. 5325-5333, Juin 2011.

[14] X. Yuan, H. Wang, J. Colinsun, et J. Zhang, "AC impedance technique in PEM fuel cell diagnosis-A review", Int. J. Hydrog. Energy, vol. 32, no 17, pp. 4365-4380, December. 2007.

[15] S. M. Rezaei Niya et M. Hoorfar, "Study of proton exchange membrane fuel cells using electrochemical impedance spectroscopy technique - A review », J. Power Sources, vol. 240, p. $281 \square 293$, oct. 2013.

[16] C. Cadet, S. Jemeï, F. Druart, et D. Hissel, « Diagnostic tools for PEMFCs: from conception to implementation », Int. J. Hydrog. Energy, vol. 39, no 20, p. 10613-10626, juill. 2014.

[17] M. Swierczynski, D. Ioan Stroe, T. Stanciu, S. Knudsen Kær, "Electrothermal impedance spectroscopy as a cost efficient method for determining thermal parameters of lithium ion batteries: Prospects, measurement methods and the state of knowledge", Journal of Cleaner Production, In Press, Corrected Proof, Available online 16 September 2016.

[18] B. Golembiewski, N.V. Stein, N. Sick, H.D. Wiemhöfer, "Identifying trends in battery technologies with regard to electric mobility: evidence from patenting activities along and across the battery value chain", Journal of Cleaner Production, 87 (2015), pp. 800-810

[19] D. Hissel, D. Candusso, et F. H. Harel, “Fuzzy-Clustering Durability Diagnosis of Polymer Electrolyte Fuel Cells Dedicated to Transportation Applications ”, IEEE Trans. Veh. Technol., vol. 4, no 5, pp. 1211-2420, September. 2007.

[20] X. Yuan, J. Colin, M. Blanco, H. Wang, J. Zhang, et D. P. Wilkinson, " AC impedance diagnosis of a 500 W PEM fuel cell stack Part I : Stack impedance ", J. Power Sources, vol. 161, pp. 920-928, 2006.

[21] X. Yuan, J. C. Sun, H. Wang, et J. Zhang, "AC impedance diagnosis of a 500W PEM fuel cell stack Part II: Individual cell impedance ", J. Power Sources, vol. 161, no 2, pp. 929-937, October. 2006.

[22] Q. Meyer, S. Ashton, O. Curnick, T. Reisch, P. Adcock, K. Ronaszegi, J. B. Robinson, et D. J. L. Brett, « Deadended anode polymer electrolyte fuel cell stack operation investigated using electrochemical impedance spectroscopy, off-gas analysis and thermal imaging », J. Power Sources, vol. 254, p. 1-9, mai 2014.

[23] Electrochemical impedance spectroscopy in PEM fuel cells: fundamentals and applications. London: Springer, 2010.

[24] M. Jouin, R. Gouriveau, D. Hissel, M.-C. Péra, et N. Zerhouni, « Prognostics and Health Management of PEMFC State of the art and remaining challenges », Int. J. Hydrog. Energy, vol. 38, n 35, p. 15307-15317, nov. 2013.

[25] A. K. S. Jardine, D. Lin, D. Banjevic, «A review on machinery diagnostics and prognostics implementing condition-based maintenance », Mech. Syst. Signal Process., vol. 20, nº 7, p. 1483-1510, oct. 2006.

[26] Z. Zheng, M.C. Péra, D. Hissel, M. Becherif, K.S. Agbli, Y. Li, " A double-fuzzy diagnostic methodology dedicated to online fault diagnosis of PEMFC stack", In Press, J. Power Sources, vol. 271, pp. 570-581 December 2014.

[27] R. Petrone, Z. Zheng, D. Hissel, M.C. Péra, C. Pianese, M. Sorrentino, M. Becherif, and N. Yousfi-Steiner, "A review on model-based diagnosis methodologies for PEMFCs", International Journal of Hydrogen Energy, Elsevier IJHE, pp. 7077-7091. 2013.

[28] A. Benmouna, M. Becherif, D. Depernet, F. Gustin, H.S. Ramadan, S. Fukuhara, "Fault diagnosis methods for Proton Exchange Membrane Fuel Cell system", International Journal of Hydrogen Energy, Elsevier IJHE, Vol 42(2), pp. 1534-1543. 


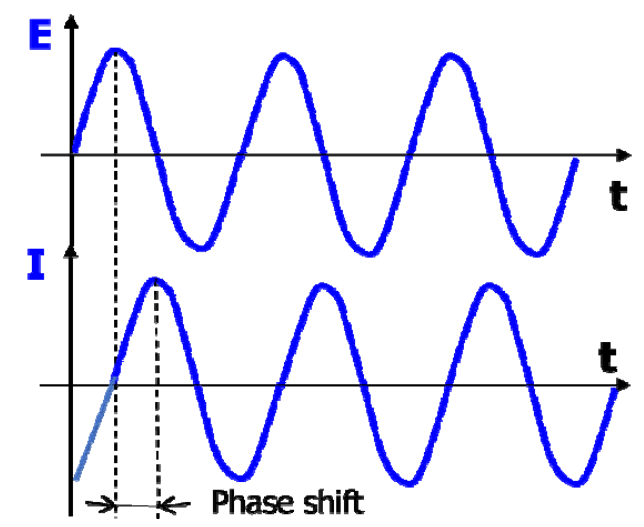

Fig. 1: Sinusoidal current response in a linear system

16 


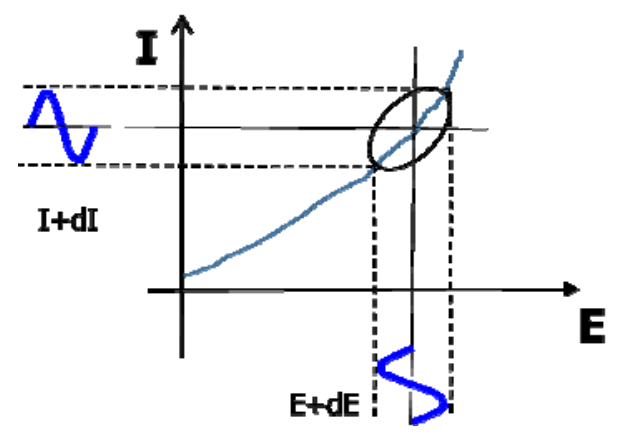

Fig. 2: Lissajous figure 


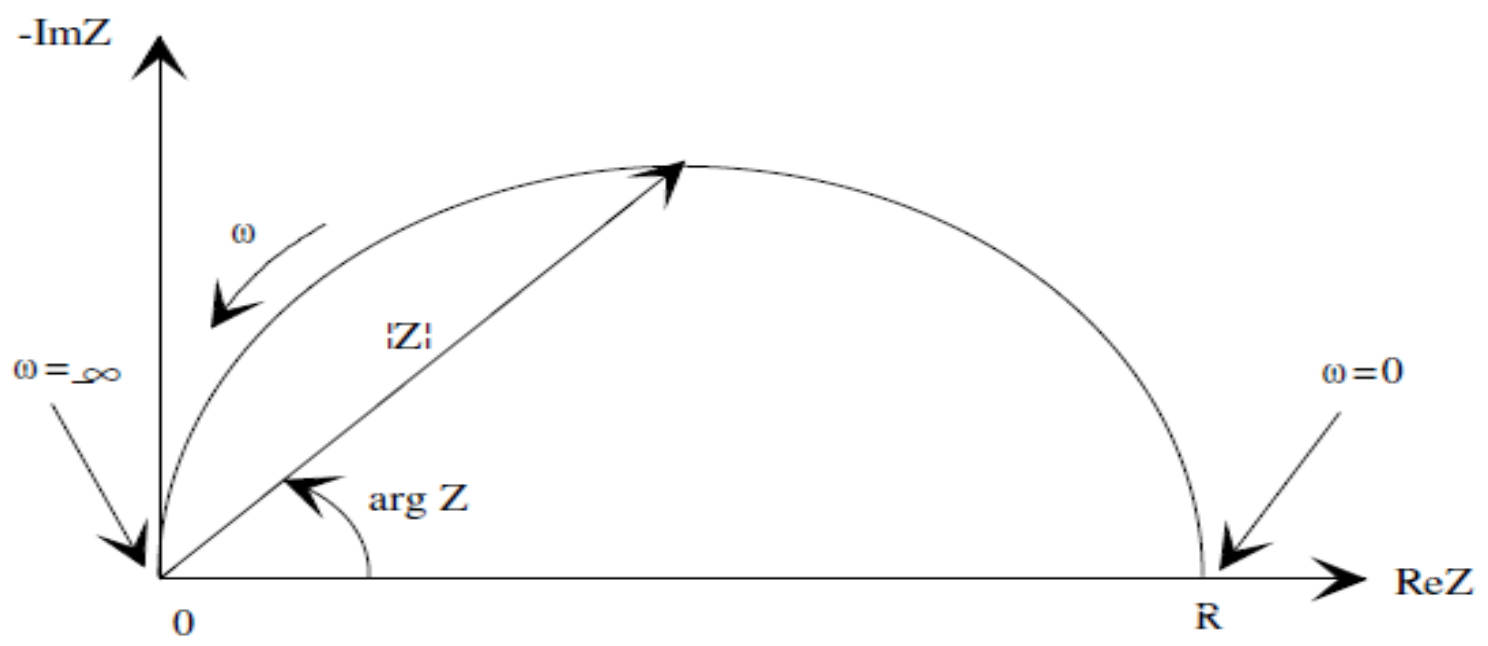

Fig. 3: Nyquist plot with impedance vector 

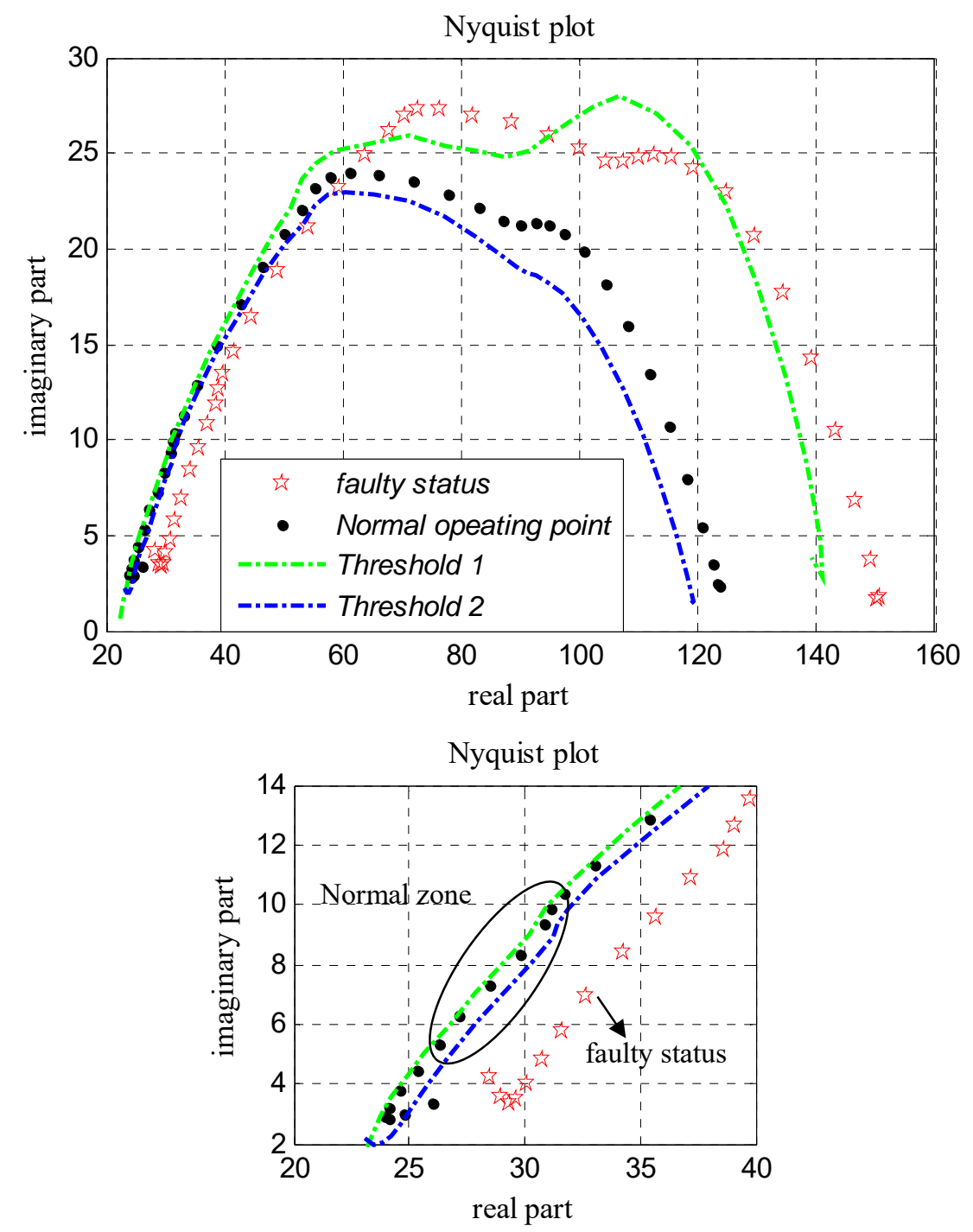

Fig.4 An example for fault prediction based on experimental data in real case: top=whole Nyquist plot, bottom: zoom on Nyquist plot 


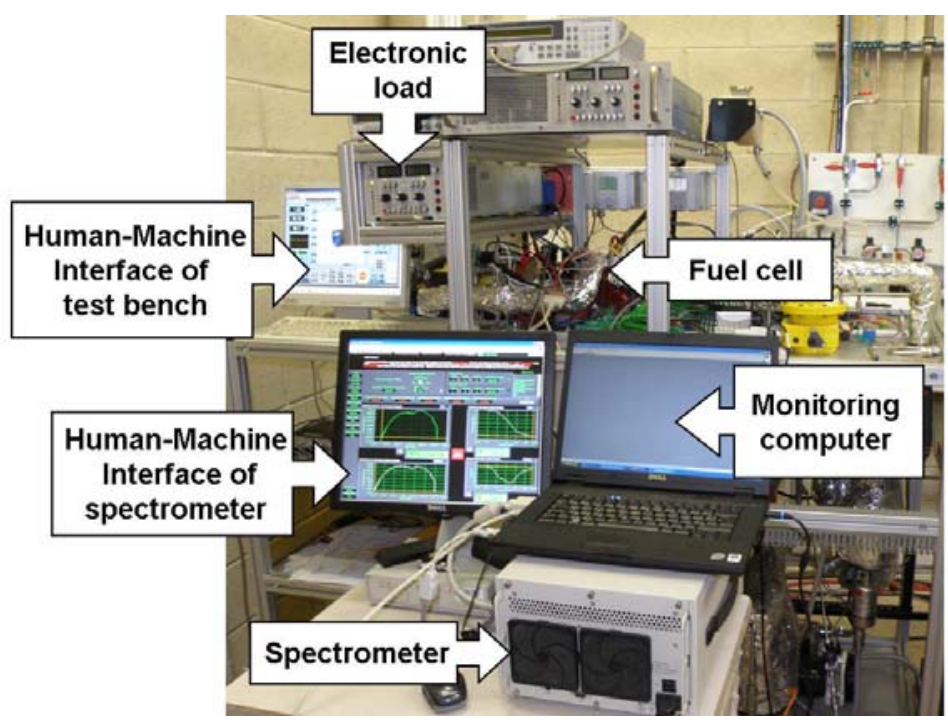

Fig.5 EIS test bench [18] 


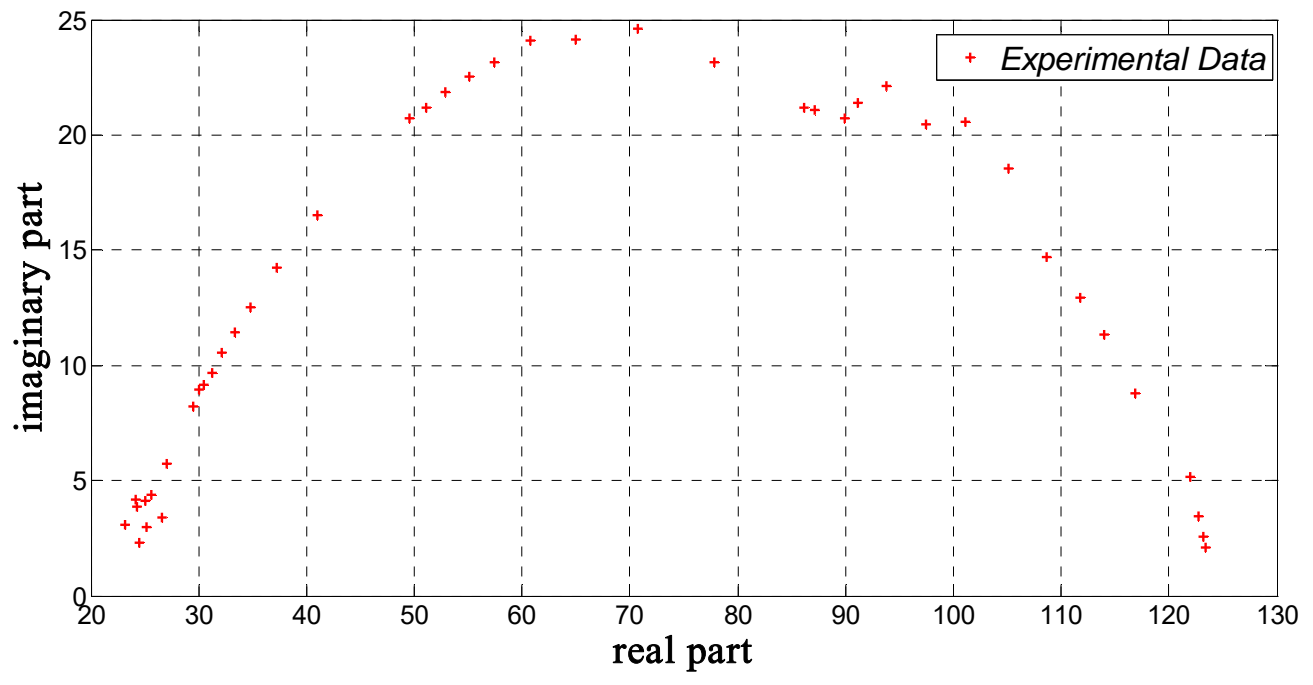

Fig.6. Experimental FC EIS (axes are in $\mathrm{m} \Omega$ ) 


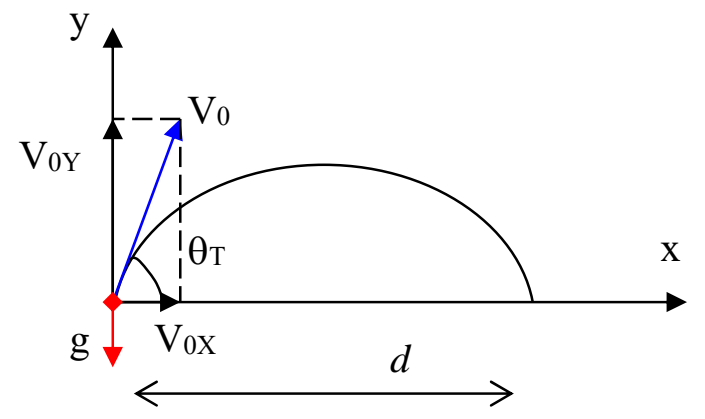

Fig. 7. Projectile trajectory motion 


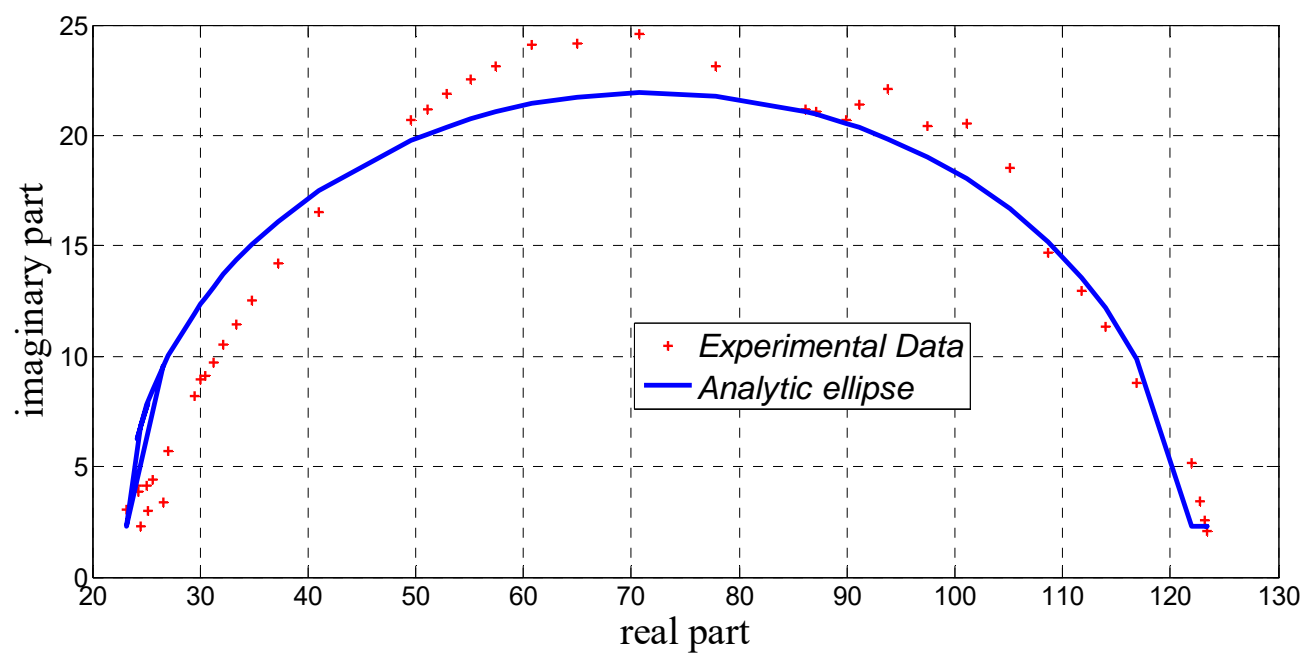

Fig. 8. Experimental EIS data and the EIS estimation using the analytic ellipse equation (axes are in $\mathrm{m} \Omega$ ) 


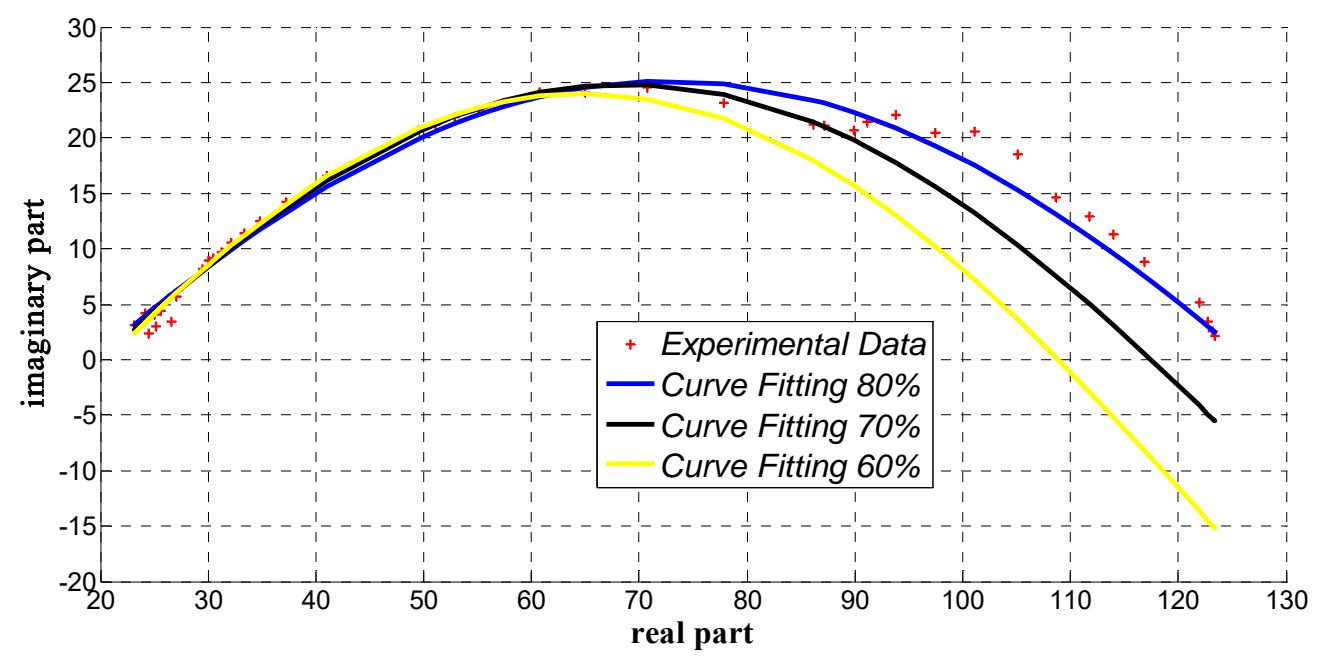

Fig. 9. Experimental FC EIS data and the obtained curve fitting using $80 \%, 70 \%$ and $60 \%$ of the experimental data sample (axes are in $\mathrm{m} \Omega$ ).

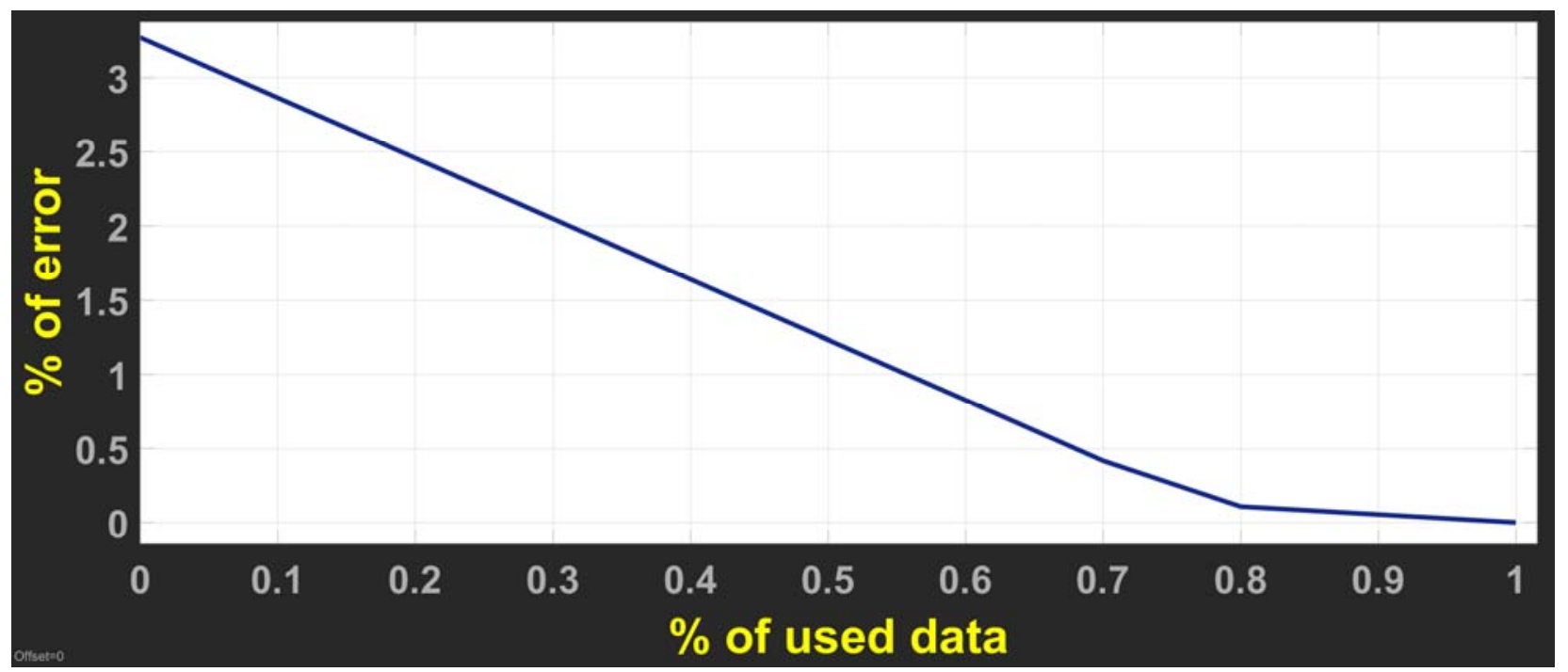

Fig. 10. Percentage of estimation error versus percentage of used data for the curve fitting estimation 


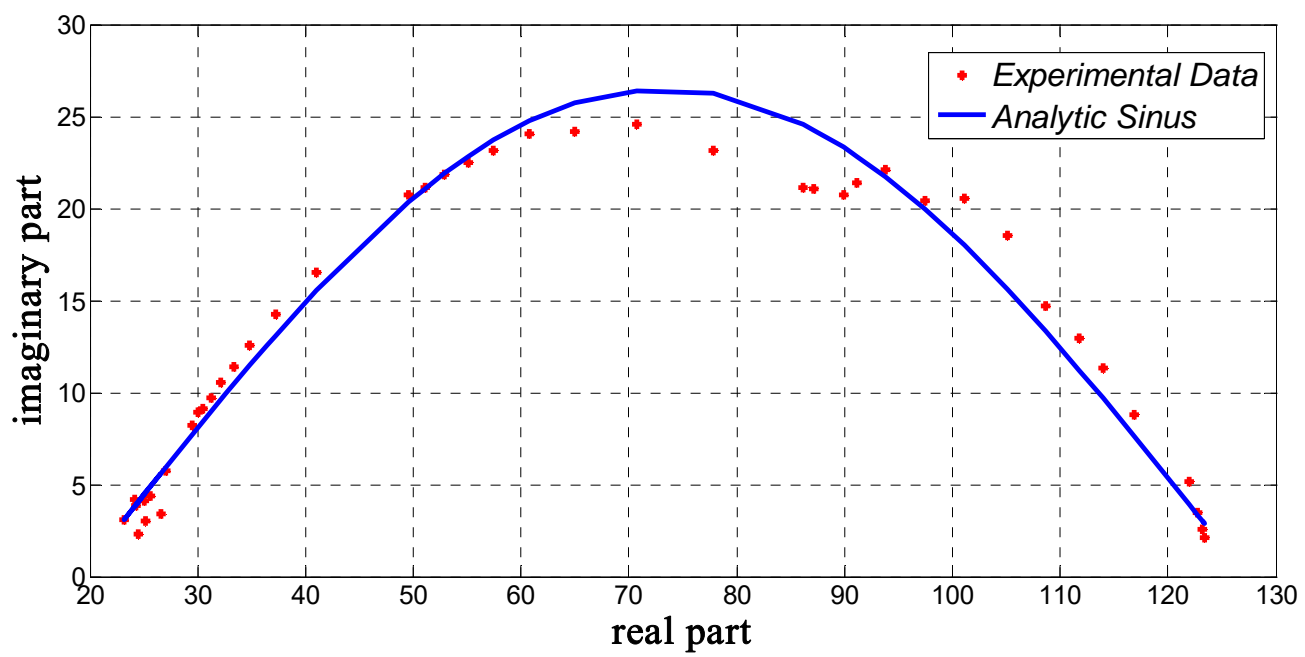

Fig. 11. Experimental FC EIS data and the EIS estimation using the analytic sinusoidal equation (axes are in $\mathrm{m} \Omega)$. 


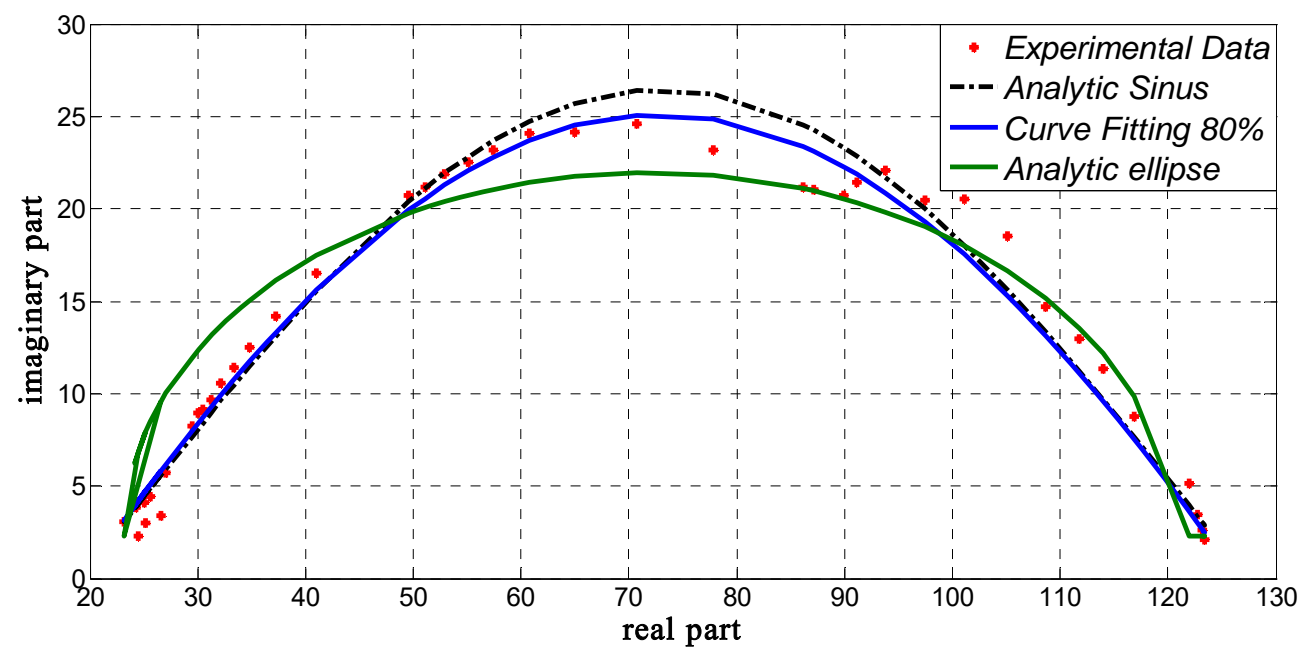

Fig. 12. Experimental FC EIS data and the EIS estimation using the curve fitting (with $80 \%$ data), the analytic ellipse equation and the analytic sinusoidal equation (axes are in $\mathrm{m} \Omega$ ).

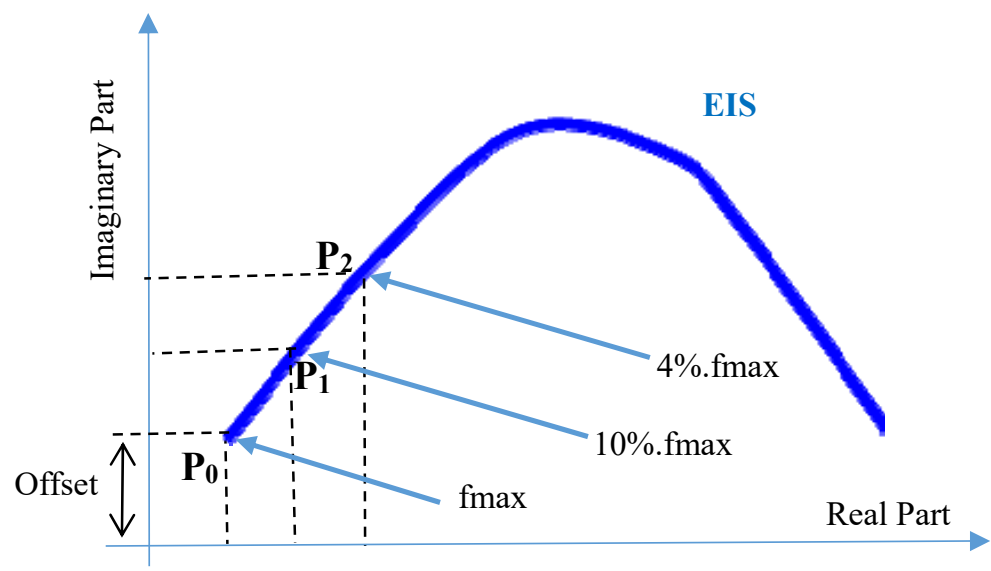

Fig. 13. Position of the three chosen points for the sinusoidal and ellipse estimation methods on the EIS curve 


\begin{tabular}{|c|c|c|c|}
\hline & Curve fitting & Analytic ellipse function & $\begin{array}{l}\text { Analytic sinusoidal } \\
\text { function }\end{array}$ \\
\hline $\begin{array}{l}\mathrm{n}^{\circ} \text { of parameters to be } \\
\text { estimated }\end{array}$ & $3=\mathrm{A}, \mathrm{B}$ and $\mathrm{C}$ & $\begin{array}{l}3=\mathrm{g}, \theta_{\mathrm{T}} \text { and } \mathrm{V}_{0} \\
d \text { is deduced }\end{array}$ & $4=\mathrm{A}, \mathrm{B}, \mathrm{C}$ and D \\
\hline $\begin{array}{l}\text { Minimum number (or } \\
\text { percentage) of experimental } \\
\text { data used for the estimation }\end{array}$ & $80 \%$ & $\begin{array}{l}3=2+1 \\
1 \text { represents the initial point } \\
\text { (offset) }\end{array}$ & $\begin{array}{l}3=2+1 \\
1 \text { represents the initial point } \\
\text { (offset) }\end{array}$ \\
\hline Performance & $\begin{array}{l}\text { Very Good if } m \geq 80 \% n \text {, } \\
\text { Relatively more time } \\
\text { computational, } \\
\text { Need to be correctly } \\
\text { initialized, } \\
\text { No sensitive to the chosen } \\
\text { experimental measures }\end{array}$ & $\begin{array}{l}\text { Acceptable, } \\
\text { Rapid, } \\
\text { Could be sensitive to the } \\
\text { chosen experimental } \\
\text { measures }\end{array}$ & $\begin{array}{l}\text { Very Good, } \\
\text { Rapid, } \\
\text { Could be sensitive to the } \\
\text { chosen experimental } \\
\text { measures }\end{array}$ \\
\hline Estimation robustness & $\begin{array}{l}\text { Could estimate the } \\
\text { remaining } 20 \% \text { of the EIS } \\
\text { points }\end{array}$ & Very helpful in estimation & Very helpful in estimation \\
\hline
\end{tabular}

Table 1. Comparison between the different EIS estimations for the FC prognostic.

\begin{tabular}{|l|l|l|}
\hline Variable & Definition & Unit \\
\hline FC & Fuel Cell & \\
\hline EIS & Electrochemical Impedance Spectroscopy & \\
\hline IS & Impedance Spectroscopy & {$[\mathrm{V}]$} \\
\hline Et & Potential at time t & {$[\mathrm{V}]$} \\
\hline E0 & Amplitude of the signal & {$[\mathrm{rad} / \mathrm{s}]$} \\
\hline$\omega$ & Radial frequency & {$[\mathrm{Hz}]$} \\
\hline $\mathrm{f}$ & frequency & {$[\mathrm{radian}]$ or $[\mathrm{degree}]$} \\
\hline$\phi$ & Phase angle & \\
\hline LTI & Linear Time Invariant & {$[\mathrm{I}]$} \\
\hline It & Current at time t & {$[\mathrm{I}]$} \\
\hline $\mathrm{I} 0$ & Amplitude of the signal & {$[\Omega]$} \\
\hline $\mathrm{Z}$ & Impedance & {$[\Omega]$} \\
\hline $\mathrm{Z} 0$ & Amplitude of the Impedance & \\
\hline arg & Argument & {$[\Omega]$} \\
\hline $\mathrm{Z} \mid$ & Module of the impedance & {$[\mathrm{V}]$} \\
\hline $\mathrm{U}$ & Voltage & \\
\hline $\mathrm{j}$ & Complex variable j2=-1 & \\
\hline PEM & Proton Exchange Membrane & \\
\hline$(\mathrm{x} 0, \mathrm{y} 0)$ & Centre of the ellipse & \\
\hline$(\mathrm{x}, \mathrm{y})$ & Coordinate along the x and y axes & {$\left[\mathrm{m} / \mathrm{s}^{2}\right]$} \\
\hline $\mathrm{a}, \mathrm{b}$ & Half distance of the major and minor axes of the ellipse & \\
\hline $\mathrm{g}$ & Gravity acceleration & \\
\hline
\end{tabular}




\begin{tabular}{|c|c|c|}
\hline $\mathrm{d}$ & Maximum distance on the $\mathrm{x}$-axis & {$[\mathrm{m}]$} \\
\hline$\theta \mathrm{T}$ & Initial projectile trajectory angle & [degree] \\
\hline V0 & Initial projectile speed & {$[\mathrm{m} / \mathrm{s}]$} \\
\hline V0x,V0y & Initial projectile speed along $\mathrm{x}$ and $\mathrm{y}$ axes & {$[\mathrm{m} / \mathrm{s}]$} \\
\hline ax,ay & Projectile acceleration along $\mathrm{x}$ and $\mathrm{y}$ axes & {$\left[\mathrm{m} / \mathrm{s}^{2}\right]$} \\
\hline $\mathrm{Vx}, \mathrm{Vy}$ & Projectile speed along $\mathrm{x}$ and $\mathrm{y}$ axes & {$[\mathrm{m} / \mathrm{s}]$} \\
\hline $\mathrm{t}$ & time & {$[\mathrm{s}]$} \\
\hline $\mathrm{V}$ & Magnitude of the projectile velocity & {$[\mathrm{m} / \mathrm{s}]$} \\
\hline $\mathrm{h}$ & Height (altitude) of the projectile & {$[\mathrm{m}]$} \\
\hline yfit & y coordinate using curve fitting & \\
\hline $\mathrm{A}, \mathrm{B}, \mathrm{C}$ & Constant parameters to be tunned & \\
\hline $\mathrm{n}$ & Maximum number of the experimental data sample & \\
\hline $\mathrm{m}$ & Number of experimental data used & \\
\hline $\mathrm{P}$ & Point $\mathrm{P}$ having the coordinate $(\mathrm{x}, \mathrm{y})$ & \\
\hline $\arg$ & Argument, $\arg (\mathrm{Z})=\arctan (\operatorname{Imaginary} \operatorname{part}(\mathrm{Z}) /$ real part $(\mathrm{Z}))$ & []degree or radian] \\
\hline
\end{tabular}

Table 2. Nomenclature

\begin{tabular}{|l|l|l|l|}
\hline P1 (freq in Hz) & P2 (freq in Hz) & $\begin{array}{l}\text { Sinusoidal method } \\
\text { estimation error in \% }\end{array}$ & $\begin{array}{l}\text { Ellipse } \\
\text { estimation error in \% }\end{array}$ \\
\hline $10(500 \mathrm{~Hz})$ & $15(250 \mathrm{~Hz})$ & 0,45 & 0,4 \\
\hline $10(500 \mathrm{~Hz})$ & $16(200 \mathrm{~Hz})$ & 0,11 & 0,216 \\
\hline $10(500 \mathrm{~Hz})$ & $17(150 \mathrm{~Hz})$ & 0,339 & 0,502 \\
\hline $10(500 \mathrm{~Hz})$ & $18(100 \mathrm{~Hz})$ & 0,357 & 0,632 \\
\hline $10(500 \mathrm{~Hz})$ & $19(50 \mathrm{~Hz})$ & 0,368 & 0,733 \\
\hline $10(500 \mathrm{~Hz})$ & $20(45 \mathrm{~Hz})$ & 0,373 & 0,738 \\
\hline
\end{tabular}

Table 2. Sensitivity results regarding the choice of frequencies for the sinusoidal and ellipse estimation methods. 